\title{
Immunohistochemical expression of caspase-1 and -9, uncleaved caspase- 3 and -6 , cleaved caspase- 3 and -6 as well as Bcl-2 in benign epithelium and cancer of the prostate
}

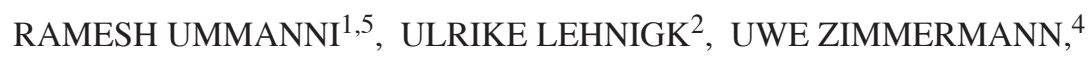 \\ CHRISTIAN WOENCKHAUS ${ }^{3}$, REINHARD WALTHER ${ }^{1}$ and JÜRGEN GIEBEL ${ }^{2}$ \\ Departments of ${ }^{1}$ Medical Biochemistry and Molecular Biology, ${ }^{2}$ Anatomy and Cell Biology, and ${ }^{3}$ Pathology, \\ ${ }^{4}$ Clinic and Policlinic of Urology, Ernst Moritz Arndt University of Greifswald, D-17487 Greifswald; \\ ${ }^{5}$ Hubertus Wald Tumorzentrum-UCCH Onkologisches Zentrum-Medizinische Klinik II, \\ Universitätsklinikum Hamburg-Eppendorf, D-20251 Hamburg, Germany
}

Received August 6, 2009; Accepted October 12, 2009

DOI: 10.3892/etm_00000008

\begin{abstract}
Activation of caspases is an essential prerequisite for induction of apoptosis. In many tumors caspases are down-regulated, while anti-apoptotic Bcl-2 is up-regulated. To elucidate their putative role in prostate cancer ( $\mathrm{PCa}$ ) we determined the expression of different caspases and Bcl-2 in benign prostate epithelium (BPE) and PCa. Paraffin-embedded prostate whole mounts were cut $(4 \mu \mathrm{m})$ and investigated immunohistochemically using monoclonal antibodies against caspase- 1 and -9 , uncleaved caspase- 3 and -6, cleaved caspase- 3 and -6 , and Bcl-2. In BPE all caspases were localized to the cytoplasm of glandular cells. In PCa we found a statistically significant reduction in cleaved caspase- 3 and -6 compared to the levels in BPE. The Bcl-2 protein was detected in the basal compartment of epithelial gland cells, but no immunostaining was noted in PCa. The decreased immunoreactivity of activated caspases probably indicates an alteration in posttranslational cleavage that may play an important role during PCa progression.
\end{abstract}

\section{Introduction}

Prostate cancer (PCa) is the second most common cause of cancer-related mortality among males in developed countries (1). It is well known that tissue homeostasis in the normal prostate gland (as in most other organs) is maintained by the quantitative relationship between the rate of cell proliferation and the rate of apoptotic cell death $(2,3)$. Thus, apoptosis comprises an important role in the development of the prostate

Correspondence to: Professor Jürgen Giebel, Department of Anatomy and Cell Biology, Ernst Moritz Arndt University, Friedrich Loeffler-Str. 23c, D-17489 Greifswald, Germany

E-mail: giebel@uni-greifswald.de

Key words: caspases, prostate carcinoma, benign prostate epithelium, immunohistochemistry, Bcl-2 and in the normal process of prostatic glandular self-renewal. Consistently, dysregulation of apoptosis represents an important mechanism of prostate carcinogenesis.

The most prominent executioners of apoptosis are represented by the family of caspases comprising initiator (caspase-1, -2, -4, -5, -8, -9 and -10) and effector caspases (caspase-3, -6 and -7) (4,5). Caspases are cysteine proteases and are synthesized as inactive proenzymes (6). On activation (cleavage), effector caspases can cleave a broad range of intracellular targets thus leading to apoptosis. Activation of caspases and initiation of different apoptotic pathways depend on the cell type (7). In a few cell types active caspase-8 activates executioners such as caspase-3, -6 and -7 in a mitochondrial-independent manner. In contrast, in other cell types apoptosis involves mitochondrial death signals mediated by the Bcl-2 family proteins. Here, active caspase- 8 cleaves Bid into a tBid (truncated form of Bid) that translocates to the mitochondria, promoting the release of cytochrome $c$ into the cytosol (8). This, in turn, leads to the formation of the apoptosome and subsequently to the activation of caspase-3. Caspase-1 (known as interleukin-1 $\beta$-converting enzyme) is also required for apoptosis (9), and caspase-9 activity is dependent on cytosolic factors (10). Cytochrome $c$ release from mitochondria initiates activation of caspase- 9 which subsequently activates caspase- 3 as an important executioner of apoptosis $(11,12)$. Caspase-6, an important effector caspase, can activate caspase- 3 resulting in apoptosis. The Bcl- 2 gene product is a potent inhibitor of apoptosis, since it stabilizes the mitochondrial membrane and blocks the release of cytochrome $c$. In turn, cytochrome $c$ can bind to caspase-9 which triggers the activation of caspase-3 $(13,14)$. Taken together, a variety of proteins, e.g., caspases and members of the Bcl-2 family, are involved in tissue homeostasis.

Although expression of caspase- 1 and -3 was shown to be decreased in PCa compared to benign prostate epithelium (BPE) (15), there is limited information on the role of caspases in PCa. Therefore, in the present study we investigated the expression of caspase- 1 and -9 , uncleaved caspase- 3 and -6 , cleaved caspase- 3 and -6 , and $\mathrm{Bcl}-2$ in PCa. 


\section{Materials and methods}

Prostate specimens. In this study, we investigated 20 primary prostate adenocarcinomas localized at the peripheral zone of the prostate from patients undergoing radical prostatectomy due to $\mathrm{PCa}$ at the Clinic and Polyclinic of Urology, University of Greifswald. No patient had received any therapy before surgery. Patient age ranged from 52 to 71 years (mean age, 61.65 years). Tissue samples and patient data were obtained and used after recommendations from the Ethics Committee of the University of Greifswald and in accordance with the Declaration of Helsinki. The entire prostate glands were fixed in $4 \%$ buffered formalin $\left(72 \mathrm{~h}, 4^{\circ} \mathrm{C}\right)$ immediately after radical prostatectomy and subsequently embedded in paraffin. Whole mount prostates were cut at $4 \mu \mathrm{m}$ and mounted on precoated glass slides (Superfrost, Menzel, Braunschweig). All sections included in this study contained BPE glands showing benign prostate hyperplasia (BPH) and $\mathrm{PCa}$.

Histopathological evaluation. Histological diagnosis and Gleason grading $(16,17)$ was performed by two experienced pathologists (C.W. and G.L.) on H\&E-stained paraffin sections. Immunostaining for active and inactive caspases was carried out in parallel on consecutive sections.

Immunohistochemistry. Expression of apoptosis-associated proteins was determined using primary antibodies against caspase-1 (Santa Cruz Biotechnology, Santa Cruz, CA, USA), uncleaved and cleaved caspase-3 and -6 (New England Biolabs, Frankfurt, Germany), caspase-9 (Acris Antibodies, Hiddenhausen, Germany), as well as Bcl-2 (Biosource, Nivelles, Belgium), employing the 4 plus $^{\mathrm{TM}}$ Universal Immunoperoxidase Detection System (Biocarta, Hamburg, Germany). After deparaffinizing and rehydration, endogenous peroxidase activity was blocked (Peroxydazed 1, Biocarta), and sections were subjected to antigen-retrieval (10 mM citrate buffer, $\mathrm{pH} 6.0)$ in a microwave oven $(700 \mathrm{~W}$ for $20 \mathrm{~min}$ ). Slides were then allowed to cool in citrate buffer (20 $\mathrm{min})$, washed in tap water (2 min), distilled water (2 min) and finally in PBS buffer (pH 7.3). Blocking with blocking reagent (5 min; Background Erazer; Biocarta) was followed by incubation with the respective antibody (overnight at $\left.4^{\circ} \mathrm{C}\right)$. Slides were washed in PBS buffer $(2 \times 5 \mathrm{~min})$, incubated with secondary antibody (10 min; Universal Link; Biocarta) and washed in buffer $(2 \times 5 \mathrm{~min})$. Slides were incubated with streptavidin-HRP solution (10 $\mathrm{min})$ and washed in PBS ( $2 \times 5 \mathrm{~min})$. Visualization was achieved by incubation with $0.1 \%$ diaminobenzidine (Sigma) in $\mathrm{PBS} / 0.01 \% \mathrm{H}_{2} \mathrm{O}_{2}(8 \mathrm{~min})$. Slides were counterstained with hematoxylin, dehydrated and mounted in Neo-mount (Merck, Darmstadt, Germany). Routine pathological observation was carried out on H\&E-stained sections.

Control reactions to demonstrate specific antibody binding were carried out by i) incubation of slides with PBS and omitting all steps, except DAB-chromogen reaction, ii) omitting the primary antibody and iii) competitive inhibition for cleaved caspase- 3 and -6 , as previously demonstrated (18). Images were captured using an Olympus BX 50 microscope equipped with an Olympus DP 10 digital camera.
Table I. Gleason score and tumour stage of the 20 PCa samples.

\begin{tabular}{cccccccc}
\hline & \multicolumn{3}{c}{ Gleason score } & & \multicolumn{2}{c}{ pT tumour stage } \\
\cline { 2 - 4 } \cline { 6 - 7 } & $3-4$ & $5-6$ & $7-8$ & & $2 \mathrm{a}-2 \mathrm{c}$ & $3 \mathrm{a}-3 \mathrm{c}$ \\
\hline No. of specimens & 4 & 9 & 7 & & 17 & 3 \\
\hline
\end{tabular}

Immunohistochemical staining for all caspases and $\mathrm{Bcl}-2$ was scored by visual assessment of ten $\mathrm{x} 40$ fields as followed: (+) $0-30 \%$ of prostate glands or tumour tissue immunopositive, $(++) 31-70 \%$ of prostate glands or tumour tissue immunopositive and $(+++)>71 \%$ of prostate glands or tumour tissue immunopositive.

Statistical analysis. Differences between caspase expression in benign and cancer tissue were analysed by a two-tailed Student's t-test. $\mathrm{P}<0.05$ was regarded as significant.

\section{Results}

Histology and grading of tumours. All prostates were evaluated by H\&E staining and revealed Gleason scores between 3 and 8 and pT stage from 2a to $3 \mathrm{c}$ (Table I). During the clinical follow-up after surgery ( 24 months) metastases were diagnosed in one patient.

Immunohistochemistry and statistical analysis. Immunohistochemistry for caspase-1 showed a weak (+) cytoplasmic staining in non-neoplastic tissue and in the tumour tissue of all samples investigated. For caspase-9, immunostaining was observed in the cytoplasm of some prostate basal cells as well as in some tumour cells of all samples (+) (Table II, figures not shown). Caspase-3 immunoreactivity was predominantly seen in the cytoplasm of basal cells of normal prostate glands (++). In most of the apical cells no immunostaining was evident (Fig. 1a). In the prostate tumour tissue of all of the patients, $>50 \%$ of tumour cells were caspase-3-positive (++) (Figs. 1b and $4 \mathrm{a}$ ). Otherwise cleaved caspase- 3 was strongly expressed in apical cells of the non-neoplastic tissue $(+++)$, whereas only a few tumour cells were immunopositive for the active caspase (+) $(\mathrm{P}<0.0001)$ (Figs. 1c and d, and 4b). Immunostaining for caspase- 6 was found in all basal and apical cells of normal prostate glands and in all tumour cells $(+++)$ (Figs. 2a and b, and $4 \mathrm{c})$. Cleaved caspase- 6 was strongly expressed (+++) in apical cells of the normal prostate glands, whereas the tumour cells showed moderate immunostaining $\quad(++) \quad(\mathrm{P}<0.0001)$ (Figs. 2c and d, and 4d). Immunohistochemical expression of Bcl-2 was noted in nearly all basal cells of the non-neoplastic prostate glands (+++). Tumour tissue, however, showed a weak immune response for $\mathrm{Bcl}-2(+)(\mathrm{P}<0.0001)$ (Figs. 3a and b, and $4 \mathrm{e})$. In the control sections no staining was evident.

\section{Discussion}

The human prostate is composed of three anatomical zones: the peripheral (PZ), central (CZ) and the transition (TZ) zone (19). The PZ comprises $70 \%$ of the prostate, and a majority of 
Table II. Summary of patient data and expression of caspases in normal and tumour tissue.

\begin{tabular}{|c|c|c|c|c|c|c|c|c|c|c|c|c|c|c|c|c|c|c|c|}
\hline \multirow[t]{3}{*}{ Specimen } & \multirow[t]{3}{*}{ A } & \multirow[t]{3}{*}{$\mathrm{Gl}$} & \multirow[t]{3}{*}{$\mathrm{G}$} & \multirow[t]{3}{*}{$\mathrm{pT}$} & \multirow[t]{3}{*}{ M } & \multicolumn{4}{|c|}{ Caspase-3 } & \multicolumn{4}{|c|}{ Caspase-6 } & \multicolumn{2}{|c|}{ Caspase-1 } & \multicolumn{2}{|c|}{ Caspase-9 } & \multicolumn{2}{|c|}{ Bcl-2 } \\
\hline & & & & & & \multicolumn{2}{|c|}{ Uncleaved } & \multicolumn{2}{|c|}{ Cleaved } & \multicolumn{2}{|c|}{ Uncleaved } & \multicolumn{2}{|c|}{ Cleaved } & \multirow[b]{2}{*}{ BPE } & \multirow[b]{2}{*}{$\mathrm{PCa}$} & \multirow[b]{2}{*}{ BPE } & \multirow[b]{2}{*}{$\mathrm{PCa}$} & \multirow[b]{2}{*}{ BPE } & \multirow[b]{2}{*}{$\mathrm{PCa}$} \\
\hline & & & & & & BPE & $\mathrm{PCa}$ & BPE & $\mathrm{PCa}$ & BPE & $\mathrm{PCa}$ & BPE & $\mathrm{PCa}$ & & & & & & \\
\hline 1 & 62 & $3+4=7$ & $3 a$ & $2 b$ & 0 & 3 & 3 & 3 & 1 & 3 & 3 & 2 & 1 & 1 & 1 & 1 & 1 & 2 & 1 \\
\hline 2 & 52 & $3+3=6$ & $2 a$ & $2 b$ & 0 & 2 & 2 & 3 & 1 & 3 & 3 & 2 & 1 & 1 & 1 & 1 & 1 & 3 & 1 \\
\hline 3 & 63 & $2+3=5$ & $1 b$ & $2 b$ & 0 & 2 & 2 & 3 & 2 & 3 & 3 & 2 & 1 & 1 & 1 & 1 & 1 & 3 & 1 \\
\hline 4 & 62 & $2+3=5$ & $2 a$ & $3 a$ & 0 & 2 & 1 & 3 & 3 & 2 & 2 & 2 & 1 & 1 & 1 & 1 & 1 & 2 & 1 \\
\hline 5 & 70 & $3+4=7$ & $3 a$ & $2 c$ & 1 & 3 & 1 & 3 & 1 & 3 & 3 & 3 & 1 & 1 & 1 & 2 & 1 & 3 & 1 \\
\hline 6 & 62 & $3+4=7$ & $3 a$ & $2 c$ & 0 & 1 & 2 & 3 & 1 & 3 & 3 & 2 & 2 & 1 & 1 & 1 & 1 & 3 & 1 \\
\hline 7 & 71 & $3+4=7$ & $3 a$ & $3 c$ & 0 & 2 & 3 & 3 & 2 & 3 & 3 & 1 & 1 & 1 & 1 & 1 & 2 & 3 & 2 \\
\hline 8 & 68 & $2+2=4$ & $1 b$ & $2 c$ & 0 & 2 & 1 & 3 & 1 & 3 & 3 & 1 & 1 & 1 & 1 & 1 & 1 & 3 & 1 \\
\hline 9 & 67 & $2+2=4$ & $1 b$ & $2 \mathrm{a}$ & 0 & 2 & 2 & 3 & 1 & 3 & 3 & 3 & 1 & 1 & 1 & 1 & 1 & 2 & 1 \\
\hline 10 & 68 & $2+3=5$ & $3 a$ & $2 c$ & 0 & 2 & 2 & 2 & 2 & 3 & 3 & 2 & 1 & 1 & 1 & 1 & 1 & 3 & 2 \\
\hline 11 & 59 & $1+2=3$ & $1 b$ & $2 b$ & 0 & 2 & 2 & 3 & 1 & 3 & 2 & 3 & 2 & 1 & 1 & 1 & 1 & 3 & 2 \\
\hline 12 & 60 & $2+3=5$ & $1 b$ & $2 b$ & 0 & 3 & 2 & 3 & 2 & 3 & 3 & 2 & 1 & 1 & 1 & 1 & 1 & 3 & 1 \\
\hline 13 & 68 & $3+4=7$ & $3 a$ & $2 c$ & 0 & 2 & 3 & 2 & 1 & 3 & 3 & 2 & 1 & 1 & 1 & 1 & 1 & 3 & 1 \\
\hline 14 & 66 & $2+3=5$ & $2 b$ & $2 a$ & 0 & 2 & 3 & 2 & 1 & 3 & 2 & 3 & 1 & 1 & 2 & 1 & 1 & 3 & 1 \\
\hline 15 & 70 & $2+3=5$ & $2 b$ & $2 b$ & 0 & 3 & 2 & 3 & 1 & 2 & 3 & 1 & 1 & 2 & 2 & 1 & 1 & 3 & 1 \\
\hline 16 & 65 & $2+3=5$ & $2 b$ & $2 \mathrm{a}$ & 0 & 2 & 2 & 3 & 3 & 3 & 3 & 2 & 1 & 2 & 2 & 1 & 1 & 3 & 2 \\
\hline 17 & 66 & $3+4=7$ & $3 a$ & $3 a$ & 0 & 3 & 2 & 3 & 1 & 3 & 3 & 2 & 1 & 1 & 1 & 1 & 2 & 2 & 2 \\
\hline 18 & 65 & $3+5=8$ & $3 a$ & $2 b$ & 0 & 3 & 3 & 3 & 1 & 2 & 3 & 1 & 2 & 1 & 1 & 1 & 1 & 3 & 2 \\
\hline 19 & 64 & $1+2=3$ & $1 b$ & $2 \mathrm{a}$ & 0 & $*$ & $*$ & $*$ & $*$ & $*$ & $*$ & $*$ & $*$ & 1 & 1 & 2 & 1 & 2 & 1 \\
\hline 20 & 65 & $2+3=5$ & $2 a$ & $2 b$ & 0 & $*$ & $*$ & $*$ & $*$ & $*$ & $*$ & $*$ & $*$ & 1 & 1 & 1 & 1 & 3 & 1 \\
\hline
\end{tabular}

A, age at diagnosis (years); Gl, Gleason score; G, grading; pT, tumour stage; M, metastasis; BPE, benign prostate epithelium, PCa, prostate cancer. Immunohistochemical score:,$+ 1 ;++, 2 ;+++, 3$. ${ }^{*}$ Not investigated due to limited material.
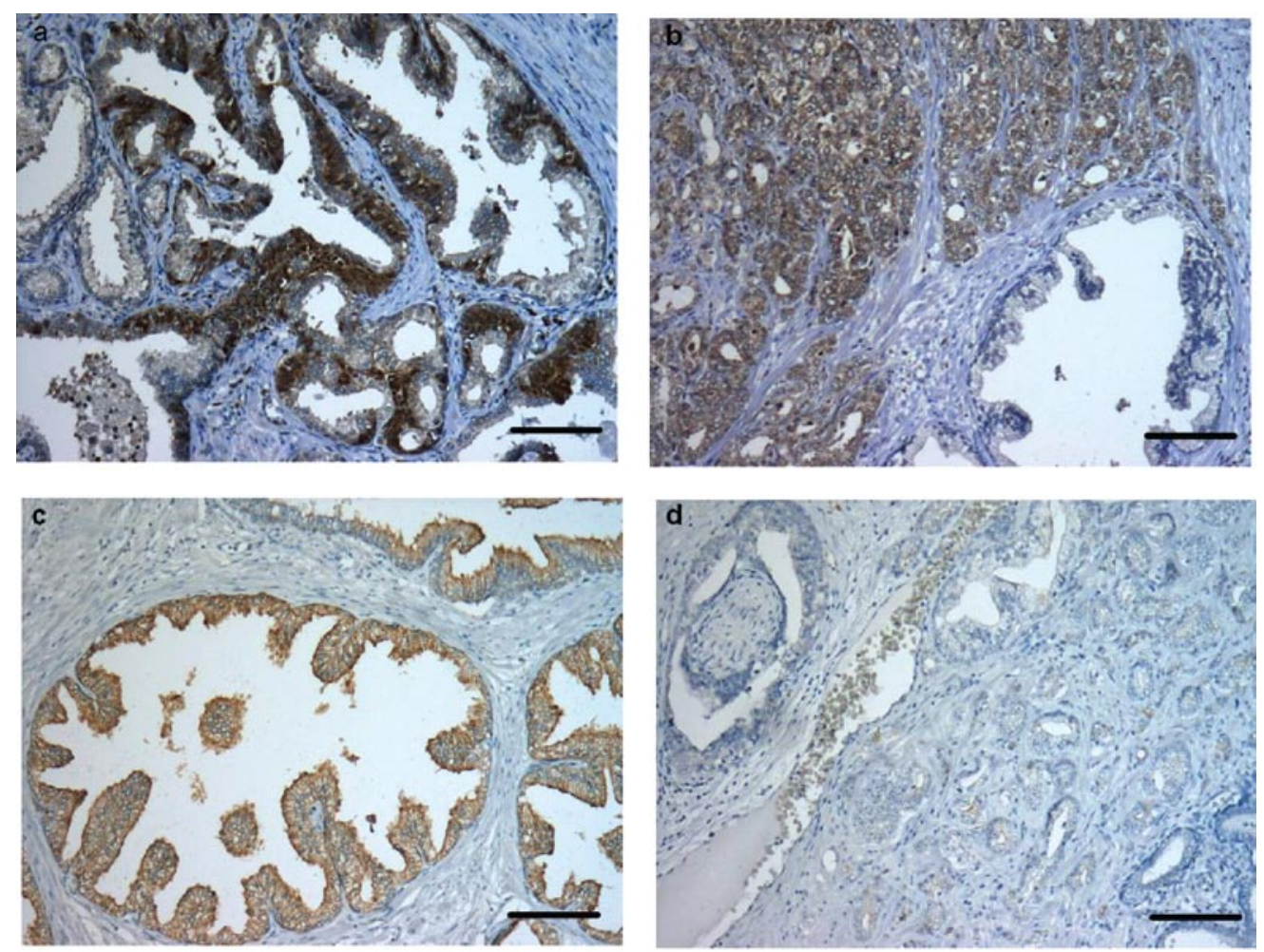

Figure 1. Immunostaining of uncleaved and cleaved caspase-3 in BPE and PCa. Uncleaved caspase-3 in BPE (a) and in PCa (b); cleaved caspase-3 in BPE (c) and in PCa (d). Bar represents $100 \mu \mathrm{m}$. 

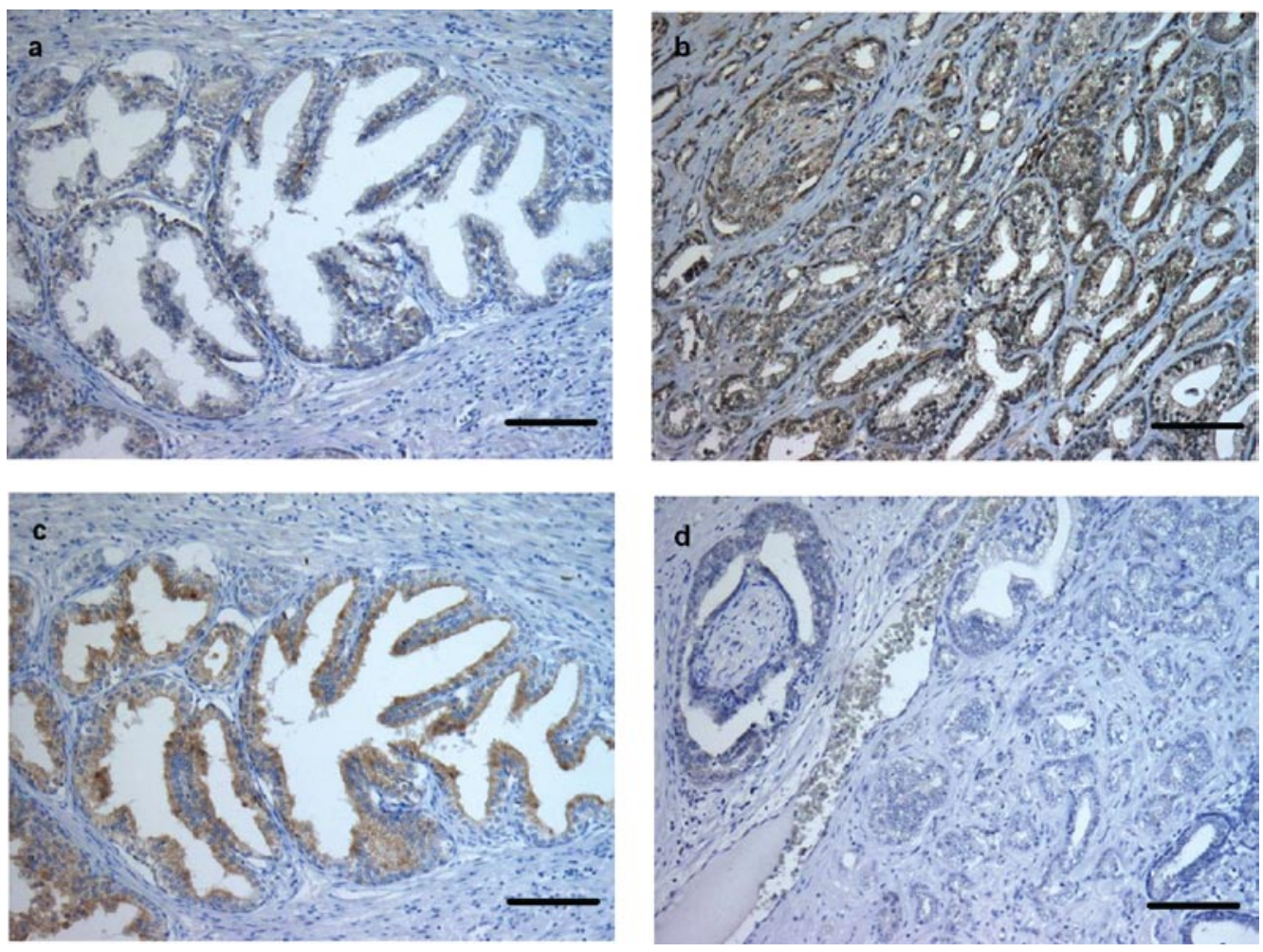

Figure 2. Immunostaining of uncleaved and cleaved caspase-6. Uncleaved caspase-6 in BPE (a) and PCa (b); cleaved caspase-6 in BPE (c) and in PCa (d). Bar represents $100 \mu \mathrm{m}$.
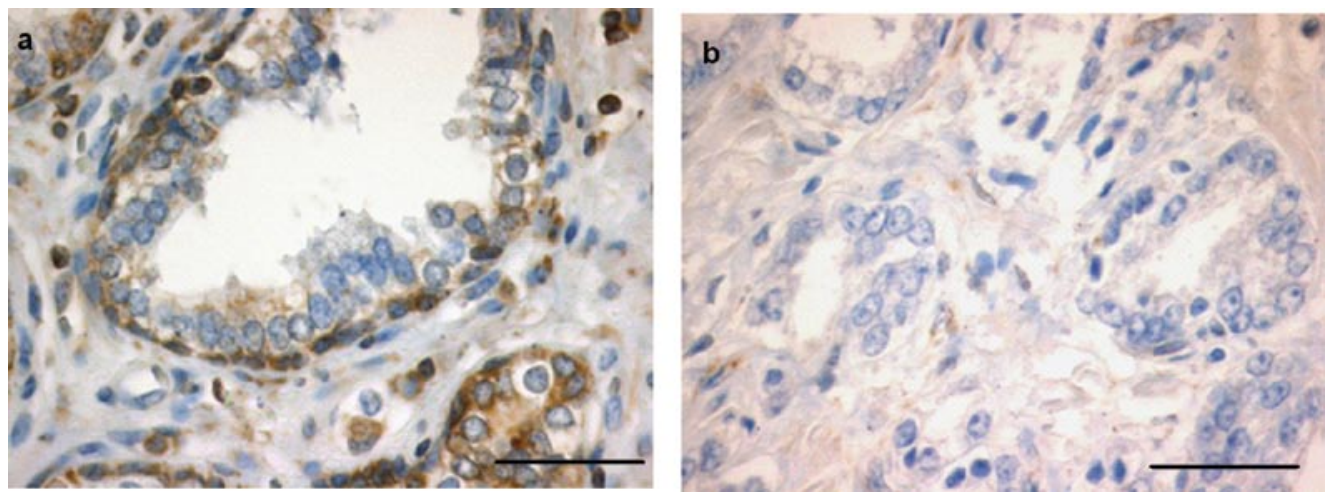

Figure 3. Immunostaining of Bcl-2 in BPE (a) and PCa (b). Bar represents $20 \mu \mathrm{m}$.

tumours originate from this zone (20,21). Most of the benign hyperplastic nodules called nodular hyperplasia, besides a few carcinomas, originate from the TZ (22). The CZ constitutes approximately $25 \%$ of the prostate and is less frequently affected by prostate diseases $(22,23)$. In the present study, we evaluated the immunohistochemical expression of caspases and $\mathrm{Bcl}-2$ in the PZ of whole mount prostate sections. Here, we demonstrated a decreased immunostaining for active caspase- 3 and -6 , while expression of uncleaved caspase- 3 and -6 appeared not to be altered in PCa compared to BPE. Previous immunohistochemical studies revealed somewhat contradictory results. For instance, immunohistochemistry showed the presence of caspase-3 (inactivated form) in basal as well as secretory cells of benign prostate hyperplasia (BPH). Moreover, increasing grades of PCa showed a signifi- cant loss of caspase-3 expression, and it was concluded that altered caspase-3 expression may represent an additional mechanism of apoptotic resistance to androgen ablation (24). On the other hand, it was shown that expression of caspase-3 did not correlate with the number of apoptotic bodies and Gleason score (25), while another study revealed that the expression of caspase-3 was reduced in poorly differentiated prostate tumours rather than well-differentiated $\mathrm{PCa}$ and BPE. Therefore, a prognostic significance has been suggested in disease progression (15). However, the findings of Ananthanarayanan et al demonstrating decreased expression of active caspase- 3 in high grade prostate intraepithelial neoplasia (PIN) and PCa (26) is in line with our findings. As in our study, immunostaining for uncleaved caspase-3 was not altered, but cleaved caspase-3 staining was significantly 


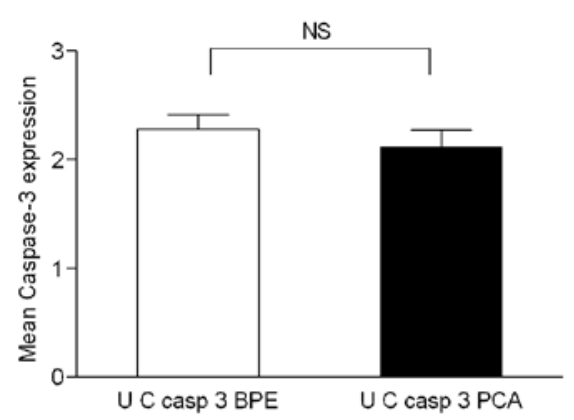

C

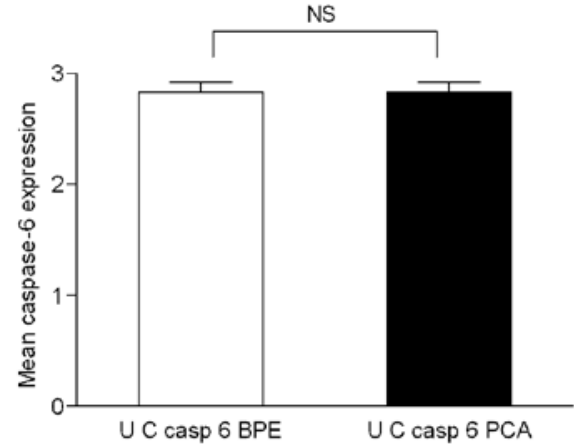

B

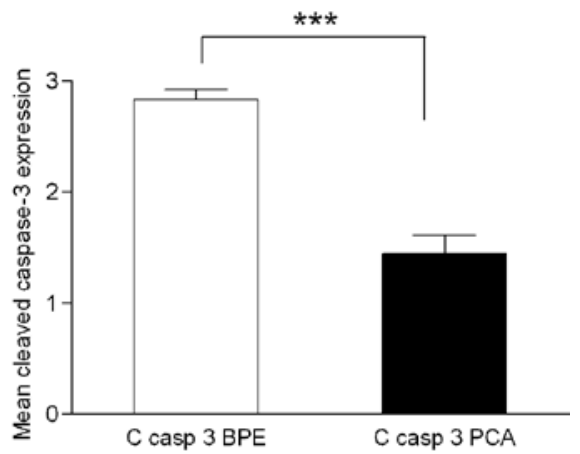

D

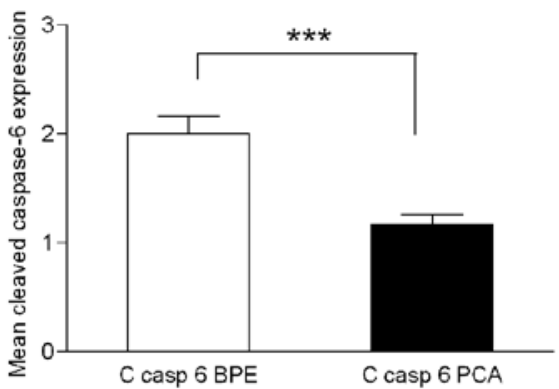

$\mathbf{E}$

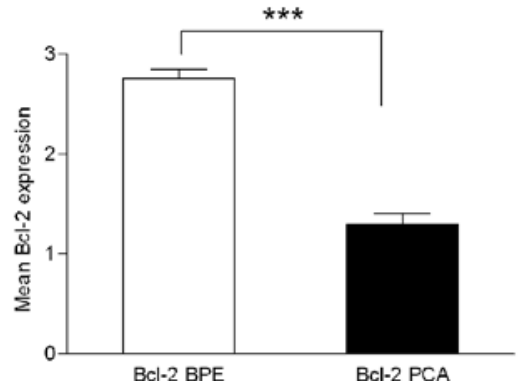

Figure 4. Mean caspase-3 (a) and cleaved caspase-3 (b) immunohistochemistry scores in normal/tumour samples. Differential expression of caspase-3 (a) in

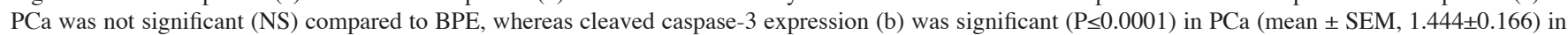
comparison with adjacent BPE (mean \pm SEM, 2.833 \pm 0.09 ). Mean caspase-6 (c) and cleaved caspase-6 (d) immunohistochemistry scores in normal/tumour samples. Differential expression of caspase-6 (c) in PCa compared to BPE was not significant (NS), whereas cleaved caspase-6 expression (d) was significant $(\mathrm{P} \leq 0.0001)$ in $\mathrm{PCa}$ (mean $\pm \mathrm{SEM}, 1.167 \pm 0.0903)$ in comparison with adjacent BPE (mean \pm SEM, 2.00 \pm 0.1617$)$. Mean values of Bcl-2 protein expression (e) in BPE and PCA samples. A 1.45-fold decrease ( $\mathrm{P} \leq 0.0001)$ in Bcl-2 expression was observed in PCa (mean $\pm \mathrm{SEM}, 1.3 \pm 0.105)$ in comparison with the BPE (mean \pm SEM, 2.75 \pm 0.099 ). UC, uncleaved; C, cleaved.

decreased in PCa. This suggests an alteration of post-translational cleavage of caspase- 3 into active caspase- 3 . Therefore, modifications of proteolytic cleavage of its precursor form could lead to lower levels of active caspase-3. Consistently, this could represent a mechanism of apoptosis suppression thus supporting cancer development. As increased caspase-3 expression has been correlated with increased apoptosis and high histologic grade in breast carcinomas (27), cancer progression appears not to be necessarily associated with the down-regulation of caspase-3.

According to our current understanding, caspase- 6 is an effector caspase that is activated downstream of caspase- 3 during apoptosis. Activation of procaspase- 6 by caspase- 3 results in an active enzyme capable of cleaving an artificially introduced lamin cleavage site. This suggests that caspase-3 is activated prior to caspase- 6 and may be responsible for the activation of caspase- 6 (28). However, these results are in conflict with a previous study showing that caspase- 6 is capable of activating caspase- 3 and that active caspase- 6 initiates activation of caspase- 3 as shown in rodent cerebellar granule cells (29). Therefore, we focused our attention towards the investigation of caspase- 6 expression in PCa. Notably, immunohistochemistry revealed no alteration in the expression of caspase-6, but a significant reduction in immunoreactivity for cleaved caspase- 6 in PCa compared to BPE as noted for cleaved caspase-3. In recent studies, the camptothesin resistant prostate cancer cell line DU145 showed decreased expression of procaspase- 6 indicating an important role of caspase- 6 in drug-induced apoptosis (30). Moreover, resveratrol-induced apoptotic signalling led to caspase-6-mediated cleavage of lamin A in colon carcinoma cells (31).

Immunohistochemical investigations for upstream caspase-1 and -9 revealed a weak immunostaining in tumour cells as well as in benign epithelial cells. In this context, it is 
worth noting that the proenzyme form of caspase-1, but not its active form, was previously detected in prostate cancer cells by Western blot analysis (15).

Previous reports suggest overexpression of $\mathrm{Bcl}-2$ in $\mathrm{PCa}$ $(32,33)$ and high grade PIN (34). This is in contrast to the results of our study, as we detected a faint staining (compared to non-neoplastic tissue) for the Bcl-2 protein in $\mathrm{PCa}$ of all of the sections investigated. Notably, a recent study did not show any significant alteration of $\mathrm{Bcl}-2$ expression in pre-malignant tumours (26). Overexpression of $\mathrm{Bcl}-2$ is linked to the restriction of cytochrome $c$ release from mitochondria which in turn activates caspase- 9 to induce apoptosis in PCa.

In conclusion, to the best of our knowledge, this is the first study to report expression of active and inactive caspases showing that caspases are expressed constitutively in neoplastic and non-neoplastic prostate cells. We suggest that activation of procaspases into active caspases could be dysregulated in cancer tissue which in turn alters apoptosis. Further investigations to elucidate altered pathways for caspase activation must be pursued in order to discover novel strategies for the treatment of cancer.

\section{Acknowledgements}

The authors thank Professor Gerhard Lorenz (Department of Pathology, Ernst Moritz Arndt University of Greifswald) for the pathological classification of prostate sections. Ramesh Ummanni was supported by the Alfried-Krupp von Bohlen und Halbach Stiftung, Graduiertenkolleg Tumorbiologie and NGFN-Plus/ NGFN-Transfer, Germany.

\section{References}

1. Landis SH, Murray T, Bolden S and Wingo PA: Cancer statistics, 1999. CA Cancer J Clin 49: 8-31, 1999.

2. Slee EA, Adrain C and Martin SJ: Serial killers: ordering caspase activation events in apoptosis. Cell Death Differ 6: 1067-1074, 1999.

3. Woo M, Hakem R, Soengas MS, Duncan GS, Shahinian A, Kagi D, Hakem A, McCurrach M, Khoo W, Kaufman SA, Senaldi G, Howard T, Lowe SW and Mak TW: Essential contribution of caspase 3/CPP32 to apoptosis and its associated nuclear changes. Genes Dev 12: 806-819, 1998.

4. Harvey NL and Kumar S: The role of caspases in apoptosis. Adv Biochem Eng Biotechnol 62: 107-128, 1998.

5. Stegh AH and Peter ME: Apoptosis and caspases. Cardiol Clin 19: 13-29, 2001.

6. Nunez G, Benedict MA, Hu Y and Inohara N: Caspases: the proteases of the apoptotic pathway. Oncogene 17: 3237-3245, 1998.

7. Scaffidi C, Fulda S, Srinivasan A, Friesen C, Li F, Tomaselli KJ, Debatin KM, Krammer PH and Peter ME: Two CD95 (APO-1/ Fas) signaling pathways. EMBO J 17: 1675-1687, 1998.

8. Luo X, Budihardjo I, Zou H, Slaughter C and Wang X: Bid, a $\mathrm{Bcl} 2$ interacting protein, mediates cytochrome $\mathrm{c}$ release from mitochondria in response to activation of cell surface death receptors. Cell 94: 481-490, 1998.

9. Thornberry NA, Bull HG, Calaycay JR, et al: A novel heterodimeric cysteine protease is required for interleukin-1 beta processing in monocytes. Nature 356: 768-774, 1992.

10. Stennicke HR, Deveraux QL, Humke EW, Reed JC, Dixit VM and Salvesen GS: Caspase-9 can be activated without proteolytic processing. J Biol Chem 274: 8359-8362, 1999.

11. Slee EA, Harte MT, Kluck RM, Wolf BB, Casiano CA, Newmeyer DD, Wang HG, Reed JC, Nicholson DW, Alnemri ES, Green DR and Martin SJ: Ordering the cytochrome c-initiated caspase cascade: hierarchical activation of caspases-2, -3, -6, -7, -8 and -10 in a caspase-9-dependent manner. J Cell Biol 144: 281-292, 1999.
12. Li P, Nijhawan D, Budihardjo I, Srinivasula SM, Ahmad M, Alnemri ES and Wang X: Cytochrome c and dATP-dependent formation of Apaf-1/caspase-9 complex initiates an apoptotic protease cascade. Cell 91: 479-489, 1997.

13. Reed JC: Bcl-2 and the regulation of programmed cell death. J Cell Biol 124: 1-6, 1994.

14. Reed JC: Mechanisms of apoptosis. Am J Pathol 157: 1415-1430, 2000.

15. Winter RN, Kramer A, Borkowski A and Kyprianou N: Loss of caspase- 1 and caspase- 3 protein expression in human prostate cancer. Cancer Res 61: 1227-1232, 2001.

16. Gleason DF and Mellinger GT: Prediction of prognosis for prostatic adenocarcinoma by combined histological grading and clinical staging. J Urol 111: 58-64, 1974.

17. Mellinger GT, Gleason D and Bailar J III: The histology and prognosis of prostatic cancer. J Urol 97: 331-337, 1967.

18. Woenckhaus C, Giebel J, Failing K, Fenic I, Dittberner T and Poetsch M: Expression of AP-2alpha, c-kit and cleaved caspase-6 and -3 in naevi and malignant melanomas of the skin. A possible role for caspases in melanoma progression? J Pathol 201: 278-287, 2003.

19. McNeal JE: Normal histology of the prostate. Am J Surg Pathol 12: 619-633, 1988.

20. McNeal JE: Regional morphology and pathology of the prostate. Am J Clin Pathol 49: 347-357, 1968.

21. McNeal JE: Origin and development of carcinoma in the prostate. Cancer 23: 24-34, 1969.

22. McNeal JE: Origin and evolution of benign prostatic enlargement. Invest Urol 15: 340-345, 1978.

23. Srodon M and Epstein JI: Central zone histology of the prostate: a mimicker of high-grade prostatic intraepithelial neoplasia. Hum Pathol 33: 518-523, 2002.

24. O'Neill AJ, Boran SA, O'Keane C, Coffey RN, Hegarty NJ, Hegarty P, Gaffney EF, Fitzpatrick JM and Watson RW: Caspase 3 expression in benign prostatic hyperplasia and prostate carcinoma. Prostate 47: 183-188, 2001.

25. Sohn JH, Kim DH, Choi NG, Park YE and Ro JY: Caspase-3/ CPP32 immunoreactivity and its correlation with frequency of apoptotic bodies in human prostatic carcinomas and benign nodular hyperplasias. Histopathology 37: 555-560, 2000.

26. Ananthanarayanan V, Deaton RJ, Yang XJ, Pins MR and Gann PH: Alteration of proliferation and apoptotic markers in normal and premalignant tissue associated with prostate cancer. BMC Cancer 6: 73, 2006.

27. Vakkala M, Paakko P and Soini Y: Expression of caspases 3, 6 and 8 is increased in parallel with apoptosis and histological aggressiveness of the breast lesion. Br J Cancer 81: 592-599, 1999.

28. Kang JJ, Schaber MD, Srinivasula SM, Alnemri ES, Litwack G, Hall DJ and Bjornsti MA: Cascades of mammalian caspase activation in the yeast Saccharomyces cerevisiae. J Biol Chem 274: 3189-3198, 1999.

29. Allsopp TE, McLuckie J, Kerr LE, Macleod M, Sharkey J and Kelly JS: Caspase 6 activity initiates caspase 3 activation in cerebellar granule cell apoptosis. Cell Death Differ 7: 984-993, 2000.

30. Reinhold WC, Kouros-Mehr H, Kohn KW, Maunakea AK, Lababidi S, Roschke A, Stover K, Alexander J, Pantazis P, Miller L, Liu E, Kirsch IR, Urasaki Y, Pommier Y and Weinstein JN: Apoptotic susceptibility of cancer cells selected for camptothecin resistance: gene expression profiling, functional analysis and molecular interaction mapping. Cancer Res 63: 1000-1011, 2003.

31. Lee SC, Chan J, Clement MV and Pervaiz S: Functional proteomics of resveratrol-induced colon cancer cell apoptosis: caspase-6-mediated cleavage of lamin A is a major signaling loop. Proteomics 6: 2386-2394, 2006.

32. McDonnell TJ, Troncoso P, Brisbay SM, Logothetis C, Chung LW, Hsieh JT, Tu SM and Campbell ML: Expression of the protooncogene bcl-2 in the prostate and its association with emergence of androgen-independent prostate cancer. Cancer Res 52: 6940-6944, 1992 .

33. Tu H, Jacobs SC, Borkowski A and Kyprianou N: Incidence of apoptosis and cell proliferation in prostate cancer: relationship with TGF-beta1 and bcl-2 expression. Int J Cancer 69: 357-363, 1996.

34. Johnson MI, Robinson MC, Marsh C, Robson CN, Neal DE and Hamdy FC: Expression of Bcl-2, Bax and p53 in high-grade prostatic intraepithelial neoplasia and localized prostate cancer: relationship with apoptosis and proliferation. Prostate 37: 223-229, 1998. 